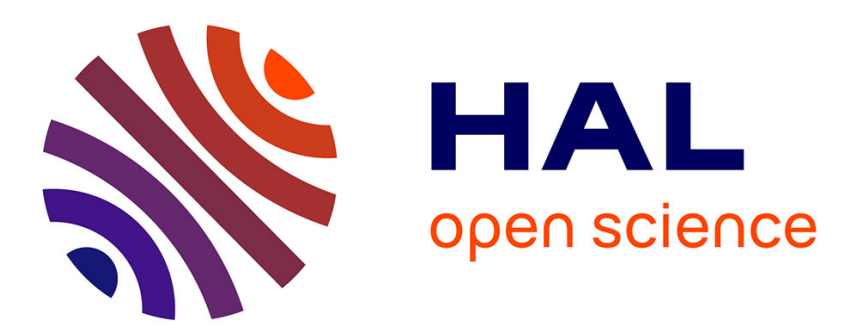

\title{
Interaction between diffusion of palm biodiesel and large strain in rubber: Effect on stress-softening during cyclic loading
}

Andri Andriyana, Ai Bao Chai, Erwan Verron, Mohd Rafie Johan

\section{- To cite this version:}

Andri Andriyana, Ai Bao Chai, Erwan Verron, Mohd Rafie Johan. Interaction between diffusion of palm biodiesel and large strain in rubber: Effect on stress-softening during cyclic loading. Mechanics Research Communications, 2012, 43, pp.80-86. 10.1016/j.mechrescom.2012.03.004 . hal-01006988

\section{HAL Id: hal-01006988 \\ https://hal.science/hal-01006988}

Submitted on 16 Jun 2014

HAL is a multi-disciplinary open access archive for the deposit and dissemination of scientific research documents, whether they are published or not. The documents may come from teaching and research institutions in France or abroad, or from public or private research centers.
L'archive ouverte pluridisciplinaire HAL, est destinée au dépôt et à la diffusion de documents scientifiques de niveau recherche, publiés ou non, émanant des établissements d'enseignement et de recherche français ou étrangers, des laboratoires publics ou privés.

\section{(c)(1)}

Distributed under a Creative Commons Attribution| 4.0 International License 


\title{
Interaction between diffusion of palm biodiesel and large strain in rubber: Effect on stress-softening during cyclic loading
}

\author{
A. Andriyana a ${ }^{\text {a }}$ A.B. Chai ${ }^{\text {a }}$, E. Verron ${ }^{\text {b }}$, M.R. Johan ${ }^{a}$ \\ a Department of Mechanical Engineering, University of Malaya, 50603 Kuala Lumpur, Malaysia \\ b Institut de Recherche en Génie Civil et Mécanique (GeM) - UMR CNRS 6183, École Centrale de Nantes, BP 92101, 44321 Nantes, France
}

In addition to fluctuating multiaxial mechanical loading, many engineering rubber components are exposed to hostile environments such as oil rich environment. In this case, the mechanical response of rubbers is affected by the interaction existed between mechanical loading and diffusion of liquid into the material. The present work attempts to investigate the above interaction and the resulting mechanical response under cyclic loading conditions in nitrile butadiene rubber (NBR) and chloroprene rubber (CR). More precisely, our focus is on the well-known stress-softening (Mullins effect) phenomenon classically observed in rubbers under cyclic loading conditions.

\author{
Keywords: \\ Rubber \\ Diffusion \\ Cyclic loading \\ Stress-softening \\ Swelling
}

\section{Introduction}

In Asian countries such as Malaysia and Indonesia, energy insecurity, increase in energy consumption, and environmental concerns are among the major driving forces for the development of biofuels as partial substitution of petroleum fuels (Jayed et al., 2011). The use of biofuels, derived from plant materials or animal fats, offers an attractive alternative for diesel engines since their use does not require extensive engine modification. If the compatibility of materials in conventional petrodiesel system is well established, the compatibility between biofuels such as palm biodiesel and engineering materials, in particularly rubbers, remain to be explored (Haseeb et al., 2010).

Rubbers are widely used in various applications such as tires, shock absorbers, seals, and gaskets in automotive industry. In a large majority of cases, they are subjected to fluctuating multiaxial loading conditions which can lead to fatigue failure (Mars and Fatemi, 2002; Verron and Andriyana, 2008; Andriyana et al., 2010). In addition, many industrial rubber components are exposed to hostile environments such as acid medium, sea water, or oil rich medium. In this case, the long-term behavior of rubbers are strongly affected by the interaction between mechanical loading and diffusion of liquids. Whenever rubbers are exposed to liquids, one main form of degradation experienced by the materials is swelling which can be described in terms of mass or volume change (Flory, 1953;
Treloar, 1975). During the swelling, liquids penetrate the polymer network and occupy positions among the polymer molecules. Consequently, the macromolecules are forced apart resulting in the swelling of material and to the decrease in its strength since the increase in chain separation yields to the reduction of secondary bonding (Callister, 2007). A number of free swelling tests investigating the diffusion of liquids in stress-free rubbers have been extensively studied (see Treloar, 1975; and references herein). Furthermore, several works investigating the interaction between diffusion of liquids and large deformation in elastomers are available in the literature, namely Baek and Srinivasa (2004), Hong et al. (2008), Soares (2009), Chester and Anand (2010), Duda et al. (2010), Deng and Pence (2010) among others. Nevertheless, no attempts have been made to relate the above interaction with the mechanical response under cyclic loading and the resulting long term fatigue behavior (Zuyev et al., 1964; Magryta et al., 2006; Abu-Abdeen, 2010).

It is well-known that under cyclic loading conditions, rubbers exhibit inelastic responses namely mechanical hysteresis and stress-softening (Verron, 2003). The hysteresis corresponds to the amount of energy loss during a cycle and in the case of dry rubber can be related to either viscoelasticity (Bergström and Boyce, 2000), viscoplasticity (Lion, 1997) and strain-induced crystallization (Trabelsi et al., 2003). Stress-softening is mainly observed during the first cycles. Indeed, for a given strain level in the uploading, the stress decreases with the number of cycle before stabilizes after certain cycles depending on the characteristics of material. This phenomenon, firstly observed by Bouasse and Carriére (1903) then intensively studied by Mullins (1948), is often referred to as 
the Mullins effect. Up to this date, no general agreement has been found either on the physical source or on the mechanical modeling of this softening at the microscopic or mesoscopic scales (Dorfmann and Ogden, 2004; Diani et al., 2009).

The present work can be regarded as a first step toward an integrated durability analysis of industrial rubber components exposed simultaneously to fluctuating multiaxial loading and aggressive environments, e.g. oil environment in biofuel systems, during their service. To this end, the understanding of the interaction between diffusion of liquids and large deformation in rubber and the resulting mechanical response under cyclic loading plays an important role. More precisely, our focus is laid on the influence of swelling on stress-softening in rubbers under cyclic loading.

The present paper is organized as follows. In Section 2, the experimental works conducted are discussed including materials, specimen geometry, compression device and the types of test. The experimental results are presented and discussed in Section 3 while concluding remarks are given in Section 4.

\section{Experimental program}

\subsection{Materials}

Rubber specimens used in this research are provided by MAKA Engineering Sdn. Bhd., Malaysia. The materials investigated are commercial grade of nitrile butadiene rubber (NBR) and chloroprene rubber $(\mathrm{CR})$ with 60 shore hardness. Biodiesel is prepared by blending palm biodiesel (provided by Am Biofuels Sdn. Bhd., Malaysia) with diesel. The analysis report of the palm biodiesel investigated is shown in Table 1. The immersion tests conducted are immersion in B0 (100\% diesel), B25 (blend of $25 \%$ of biodiesel and $75 \%$ of diesel), B75 (blend of $75 \%$ of biodiesel and $25 \%$ of diesel) and B100 (100\% biodiesel). All blend percentages are given in volume basis.
Table 1

Properties of B100 palm biodiesel.

\begin{tabular}{lllc}
\hline Test & Unit & Methods & Results \\
\hline Ester content & $\%(\mathrm{~m} / \mathrm{m})$ & EN 14103 & 96.9 \\
Density at $15{ }^{\circ} \mathrm{C}$ & $\mathrm{kg} / \mathrm{m}^{3}$ & EN ISO 12185 & 875.9 \\
Viscosity at $40^{\circ} \mathrm{C}$ & $\mathrm{mm}^{2} / \mathrm{s}$ & EN ISO 3104 & 4.667 \\
Flash point & ${ }^{\circ} \mathrm{C}$ & EN ISO 3679 & 168 \\
Cetane number & - & EN ISO 5165 & 69.7 \\
Water content & $\mathrm{mg} / \mathrm{kg}$ & EN ISO 12937 & 155 \\
Acid value & $\mathrm{mgKOH} / \mathrm{g}$ & EN ISO 3679 & 0.38 \\
Methanol content & $\%(\mathrm{~m} / \mathrm{m})$ & EN 14110 & $<0.01$ \\
Monoglyceride content & $\%(\mathrm{~m} / \mathrm{m})$ & EN 14105 & 0.67 \\
Diglyceride content & $\%(\mathrm{~m} / \mathrm{m})$ & EN 14105 & 0.2 \\
Triglyceride content & $\%(\mathrm{~m} / \mathrm{m})$ & EN 14105 & 0.2 \\
Total glycerine & $\%(\mathrm{~m} / \mathrm{m})$ & EN 14105 & 0.25 \\
\hline
\end{tabular}

\subsection{Specimen geometry and compression device}

In order to investigate the interaction between diffusion and large deformation in rubbers and its resulting mechanical response under cyclic loading condition, an annular rubber specimen having height, outer diameter, and wall thickness of $10 \mathrm{~mm}, 50 \mathrm{~mm}$, and $6 \mathrm{~mm}$, respectively is considered. The specimens are placed in a home-made compression device as illustrated in Fig. 1. As depicted in this figure, four stainless steel plates are arranged successively and separated by three sets of spacer bar having different heights: $8 \mathrm{~mm}, 9 \mathrm{~mm}$, and $9.8 \mathrm{~mm}$. Four rubber specimens are placed in each level. The plates are tightened using bolts and nuts until they are uniformly in contact with the respective spacer bar. Since the height of the rubber specimen is $10 \mathrm{~mm}$, the above arrangement allows the application of different engineering pre-compressive strains to the specimen: $2 \%, 10 \%$ and $20 \%$. The device containing rubber specimens is subsequently immersed into different palm biodiesel blends for durations of 30 and 90 days. The details of the immersion tests is given in Table 2 . In order to determine the swelling level (change of volume), the volume of the specimen is measured before

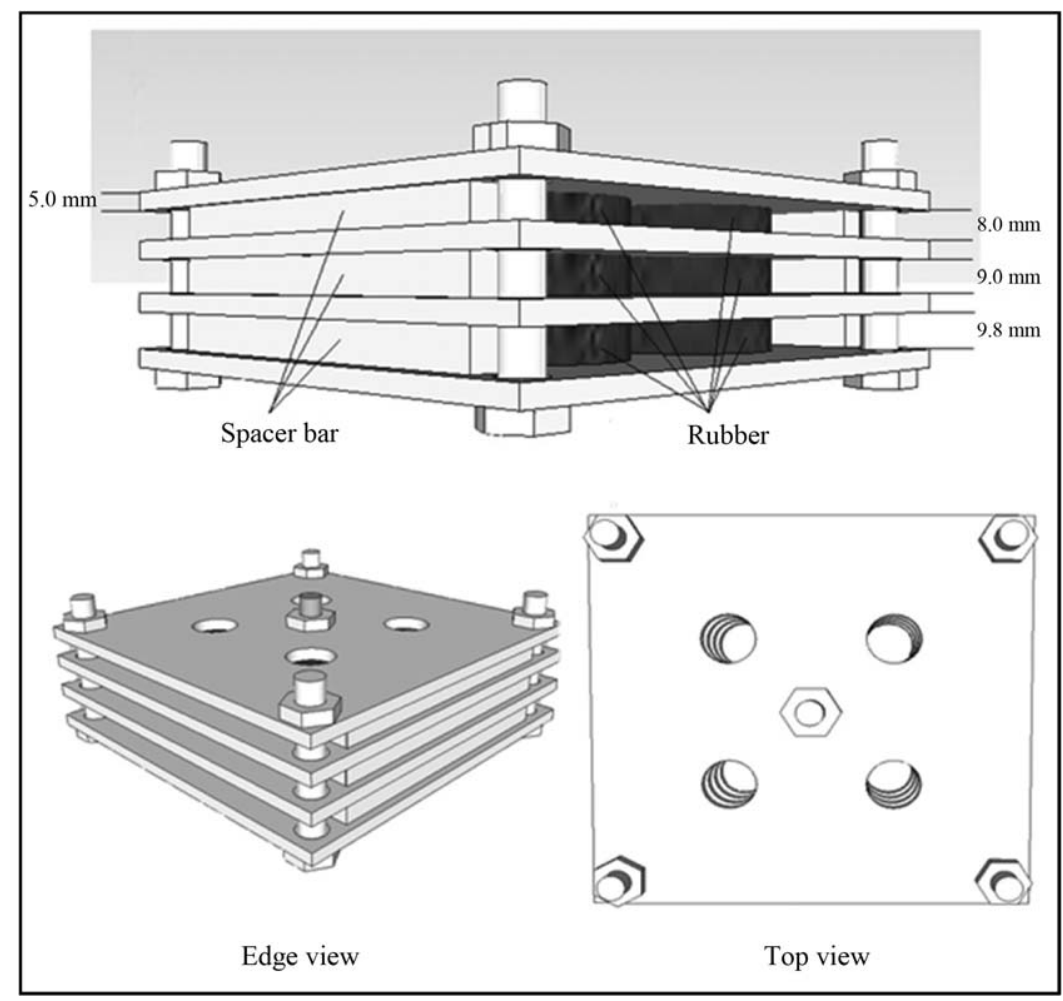

Fig. 1. Home-made compression device for the observation of the coupling between diffusion and large deformation in rubbers (Chai et al., 2011). 

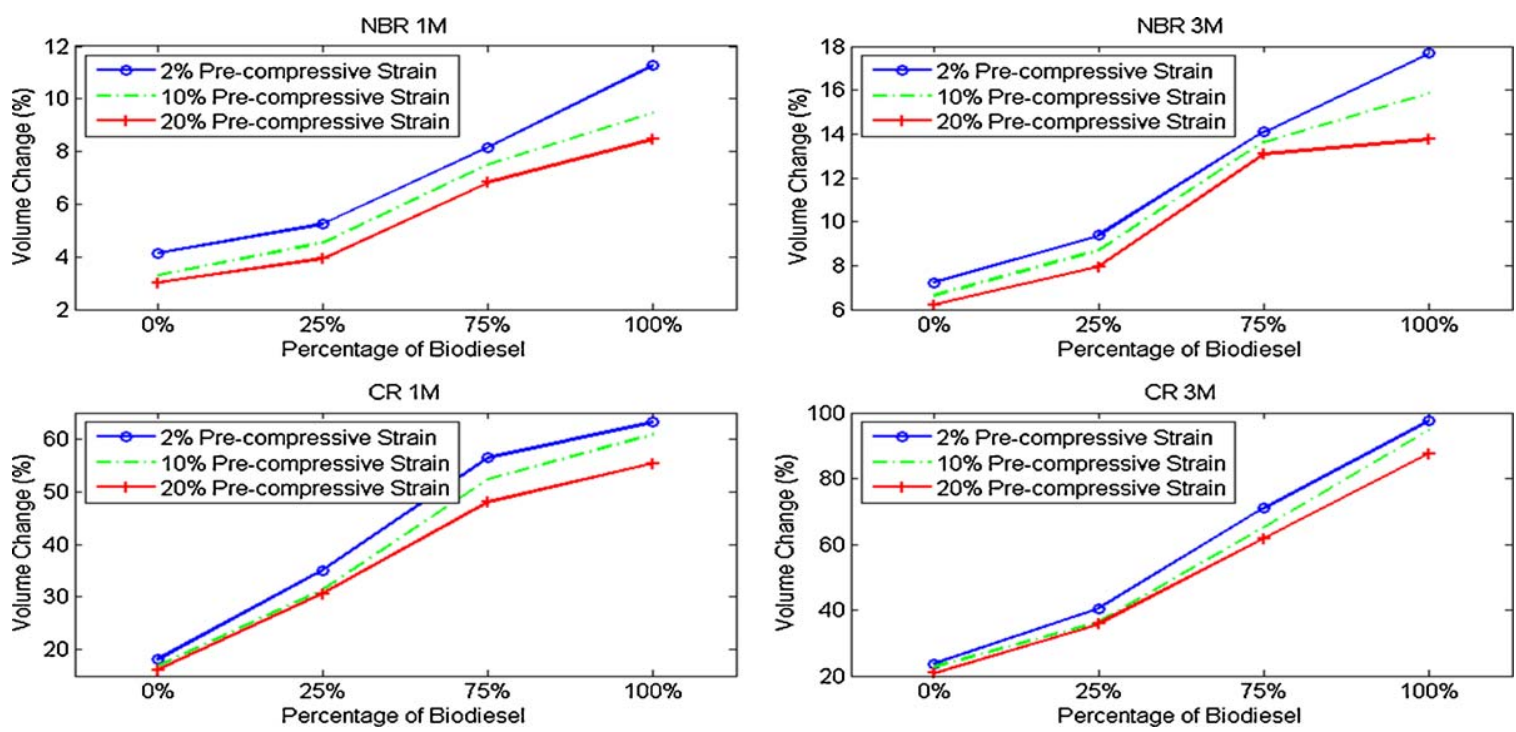

Fig. 2. Volume changes of NBR and CR at different compressive strains after 1 month (1M) and 3 months (3M) of immersion in different biodiesel blends.

Table 2

Immersion tests.

\begin{tabular}{lll}
\hline Biodiesel blend & Level of pre-compressive strain $(\%)$ & Immersion duration \\
\hline B0 & $2 / 10 / 20$ & $30 / 90$ days \\
B25 & $2 / 10 / 20$ & $30 / 90$ days \\
B75 & $2 / 10 / 20$ & $30 / 90$ days \\
B100 & $2 / 10 / 20$ & $30 / 90$ days \\
\hline
\end{tabular}

and after the immersion. The test procedure for the measurement of volume change can be summarized as followed:

1. Before the immersion, the weight of the rubber specimen is measured in air and in distilled water. The specimen is then quickly dipped into alcohol and blotted dry with filter paper.

2. After weight measurement, the rubber specimens are placed in sequence on the compression plates. Grease is applied on the surface of the specimens that are in contact with the compression plate to avoid bulging of the specimens. Thereby ensuring the specimens to be in a simple uniaxial compressive stress state.

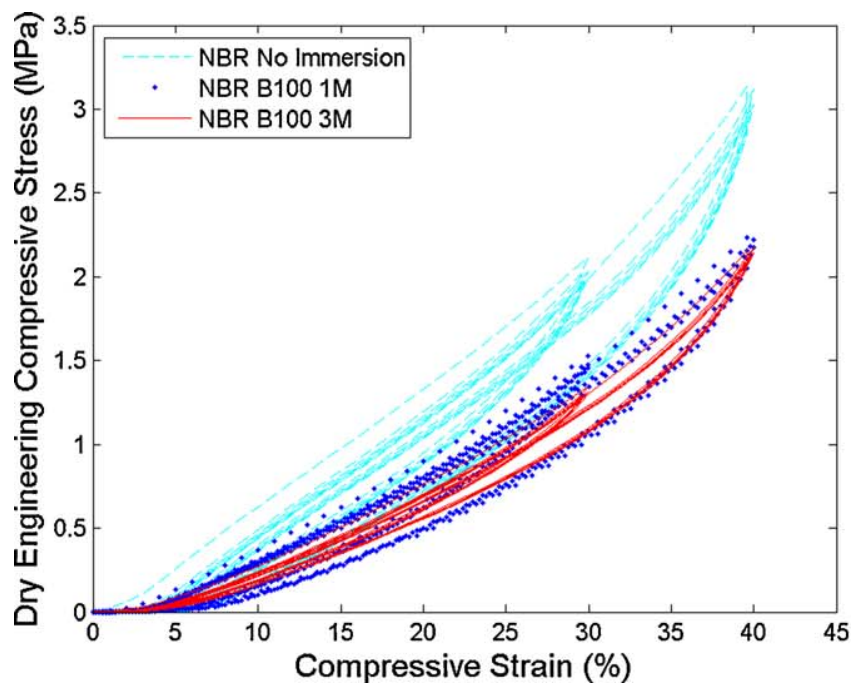

3. Bolts and nuts are used to tighten the compression device until the compression plates are uniformly in contact with the spacers. The device containing rubber specimens is subsequently immersed completely into different biodiesel blends for 30 or 90 days.

4. At the end of each immersion period, the specimens are removed from the compression device and quickly dipped into acetone; it is then cleaned with filter paper to remove the excess oil. The specimens are left for 30 min to allow for recovery before any measurement is made after immersion.

5. Step 1 is repeated to measure the weight of rubber specimen after immersion.

The percentage of volume change is calculated using the following relation (Trakarnpruk and Porntangjitlikit, 2008):

$$
=\frac{\left(M_{2}-M_{4}\right)-\left(M_{1}-M_{3}\right)}{\left(M_{1}-M_{3}\right)} \times 100
$$

where $M_{1}$ and $M_{2}$ are the mass in air ( $\mathrm{g}$ ) before and after immersion while $M_{3}$ and $M_{4}$ are mass in water ( $\mathrm{g}$ ) before and after immersion.

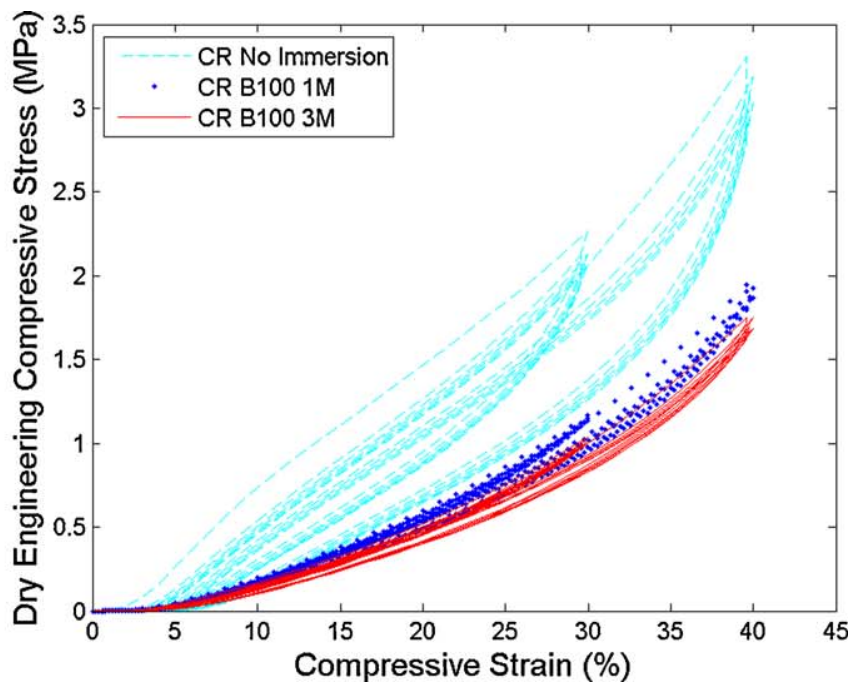

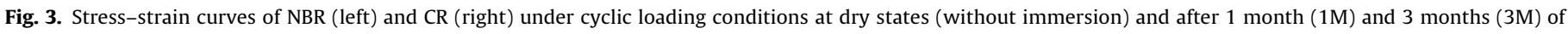
immersion in B100. Results correspond to pre-compressive strain of $2 \%$. 
For each biodiesel content, pre-compressive strain and immersion duration, at least four specimens are used in the measurement of volume change.

Remark 2.1. In practice, the $2 \%$ pre-compressive strain is so small that its effect on the macroscopic mechanical response is negligible. Nevertheless, this level of strain is retained to represent initially stress-free condition while ensuring that the diffusion occurs only along radial direction. The details about the compression device is given in Chai et al. (2011).

\subsection{Mechanical testing}

After each period of immersion, the mechanical response of the swollen rubbers under cyclic loading condition is investigated. For this purpose, cyclic tests using Instron 5500 uniaxial test machine equipped with $10 \mathrm{kN}$ load cell at room temperature are conducted. To ensure uniform displacement control on the specimens, circular compression plates are attached to the machine. The experimental setup is connected to a computer to record the experimental data. All tests are conducted in compression at a constant displacement rate of $0.1 \mathrm{~mm} / \mathrm{s}$ to avoid excessive increase in the temperature of the specimens, i.e. thermal effects are not considered in the present study. The specimens are subjected to cyclic compressive loading at two different maximum engineering compressive strains: $30 \%$ and $40 \%$ of 6 cycles each.

Remark 2.2. It is important to remember that the word "strain" used in this study corresponds to the engineering strain defined with respect to the unswollen-unstrained configuration.

\section{Results and discussion}

\subsection{Change in volume}

Fig. 2 presents the volume changes experienced by NBR and CR for different contents of biodiesel, different durations of immersion and different pre-compressive strains. The graphs clearly show the increase of volume in both materials after immersion. In general, it is found that the volume increases with biodiesel content and duration of immersion. As indicated in this figure, CR shows significantly higher change in volume than NBR. Indeed, it is observed that the volume change ranges between $18-98 \%$ and $3-18 \%$ for CR and NBR respectively.

The pre-compressive strain appears to give restriction to the diffusion of liquid into rubber. Indeed, as the pre-compressive strain increases, the resulting volume change decreases. The corresponding results can be explained by the fact that as higher pre-compressive strain is introduced, the initial effective area provided by the rubber specimens for diffusion of liquid to occur becomes smaller. Moreover, as evoked by Treloar (1975), the presence of compressive stress in the material reduces diffusion since the hydrostatic part of this stress state is positive. In the next subsection, only results that correspond to $2 \%$ pre-compressive strain are presented since the pre-compressive strain of $2 \%$ yields to the highest level of swelling.

\subsection{Stress-softening}

The stress-strain responses under cyclic compressive loading conditions at two different maximum compressive strains of previously non-immersed (dry) and immersed (swollen) NBR and CR are depicted in Fig. 3. For each value of maximum compressive strain, the specimen experiences six cycles of loading. It is important to highlight that the stress given in this figure is expressed with respect to the unswollen-unstrained configuration (dry crosssection). As indicated in this figure, no significant difference in the

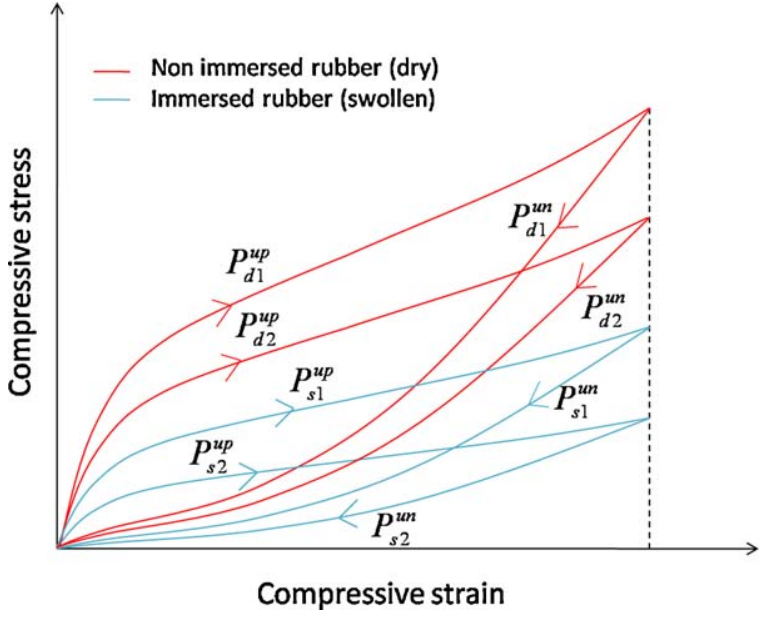

Fig. 4. Illustration of two first cycles stress-strain curve of previously nonimmersed (dry) and immersed (swollen) rubbers under cyclic loading.

nature of stress-strain behavior between dry and swollen rubbers is observed. Nevertheless, for a given strain, lower stresses are recorded for swollen rubbers; and CR exhibits larger stress drop than NBR. In either dry or swollen state, NBR and CR exhibit inelastic responses, i.e. mechanical hysteresis and stress-softening. The former, characterized by the difference between uploading and unloading paths during one cycle, decreases with loading cycle and stabilizes after five cycles. Moreover, the mechanical hysteresis exhibited by dry CR is slightly larger than that of dry NBR. For both materials, the presence of liquids appears to decrease the size of hysteresis loop. The latter, i.e. stress-softening characterized by the difference in stress during the first few uploading, disappears after five cycles.

Before proceeding further with the nature of stress-softening in the presence of biodiesels, it is important to recall the difference between the decrease in stress associated with the decrease in strength of rubber and the decrease in stress associated with stress-softening. The former compares the stress level during the first uploading between dry rubber and swollen rubber. The latter compares the stress level during the first and the second uploadings in one rubber (either dry or swollen). To characterize the former and the latter, we use the terms stress drop and stress-softening respectively defined by (see Fig. 4 ).

Stress drop $=\frac{P_{d 1}^{\mathrm{up}}-P_{s 1}^{\mathrm{up}}}{P_{d 1}^{\mathrm{up}}}$

Stress - softening $($ dry $)=\frac{P_{d 1}^{\text {up }}-P_{d 2}^{\text {up }}}{P_{d 1}^{\text {up }}}$;

$$
\text { Stress }- \text { softening }(\text { swollen })=\frac{P_{s 1}^{\text {up }}-P_{s 2}^{\text {up }}}{P_{s 1}^{\text {up }}}
$$

where $P_{d 1}^{\text {up }}$ is the stress in dry rubber during uploading of the first cycle, $P_{d 2}^{\text {up }}$ is the stress in dry rubber during uploading of the second cycle, $P_{s 1}^{\mathrm{up}}$ is the stress in swollen rubber during uploading of the first cycle and $P_{s 2}^{\text {up }}$ is the stress in swollen rubber during uploading of the second cycle. The use of Eq. (3) for the definition of stress-softening implies that we only focus on the softening which occurs between the first and the second uploading, i.e. further stress-softening after the second uploading is not considered. In the next paragraph, the evolution of stress drop and stress-softening in the presence of biodiesel is discussed with emphasis being given in the latter. Furthermore, the next discussion is restricted only to results related to 

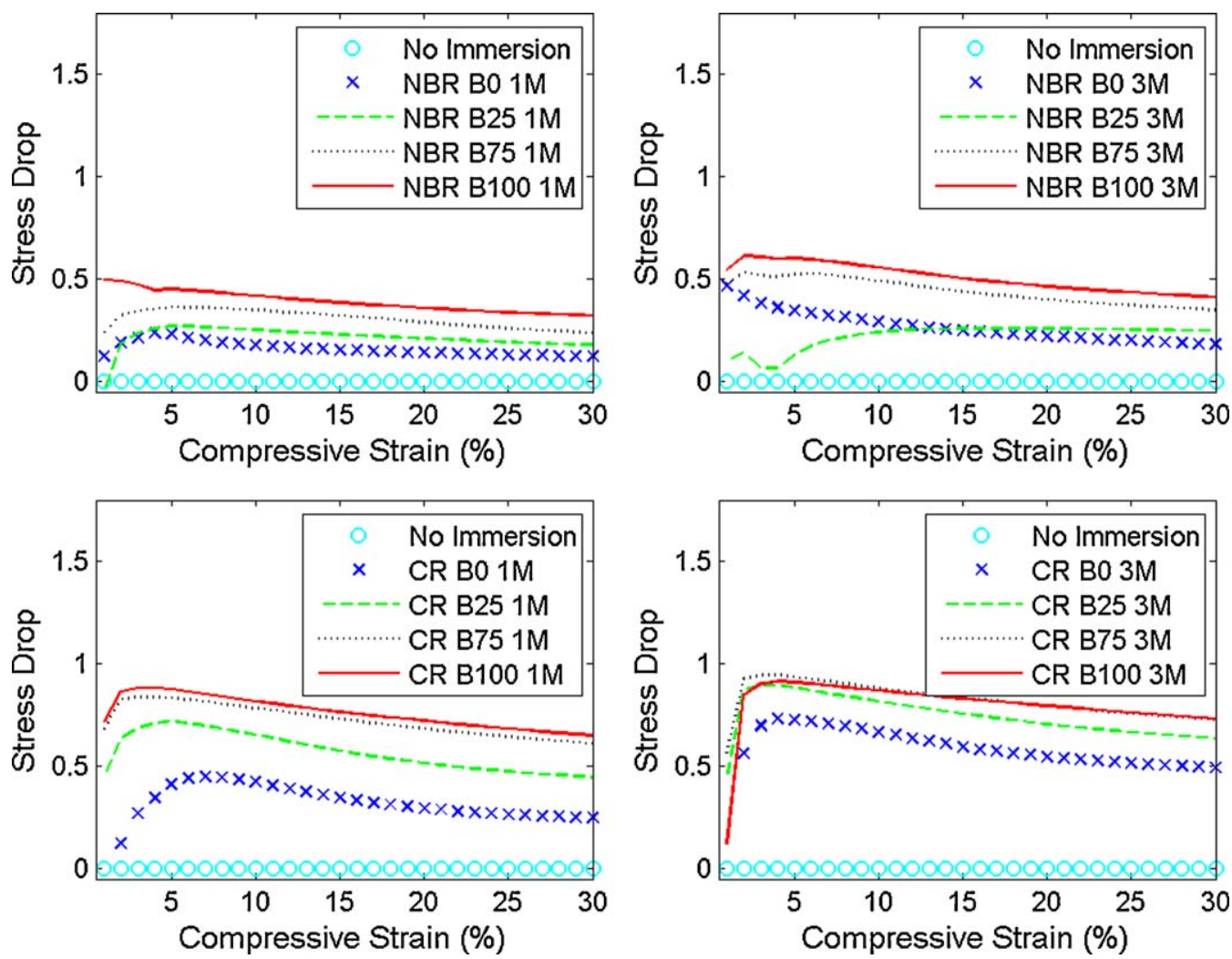

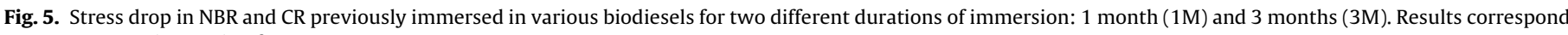
to pre-compressive strain of $2 \%$.

maximum applied cyclic compressive strain of $30 \%$ since the data at larger strains shows similar trend.

Remark 3.3. In order to compare the stress drop and stresssoftening of the materials in different biodiesels and different immersion durations, it is important to remember that for swollen rubbers, the stresses $P_{s 1}^{\text {up }}$ and $P_{s 2}^{\text {up }}$ have to be expressed with respect to the unswollen-unstrained configuration.

The stress drop exhibited by NBR and CR are shown in Fig. 5. Note that, the stress drop in dry (non-immersed) rubbers is zero by definition. As depicted in this figure, both NBR and CR experience a stress drop in the presence of biodiesels. Moreover, in the range of $5 \%-30 \%$ strain, the stress drop appears to be decreasing slightly with the applied strain. However, the corresponding drop increases with the biodiesel content and duration of immersion, i.e. the strength of rubber decreases further with the increase of biodiesel content and duration of immersion. For given biodiesel content and duration of immersion, CR exhibits larger stress drop than NBR. The high level of swelling experienced by CR as shown in Fig. 2 contributes significantly to the decrease of its strength.

Concerning stress-softening, it generally decreases as the strain level approaches the maximum strain previously endured by the material as classically observed in rubber under cyclic loading conditions (Diani et al., 2009). Unlike the stress drop, an opposite trend is found in stress-softening, i.e. the presence of liquids decreases stress-softening as shown in Figs. 6-10. Initially, at dry state, CR exhibits slightly higher level of stress-softening than NBR as depicted in Fig. 6. Nevertheless, as the material is immersed for
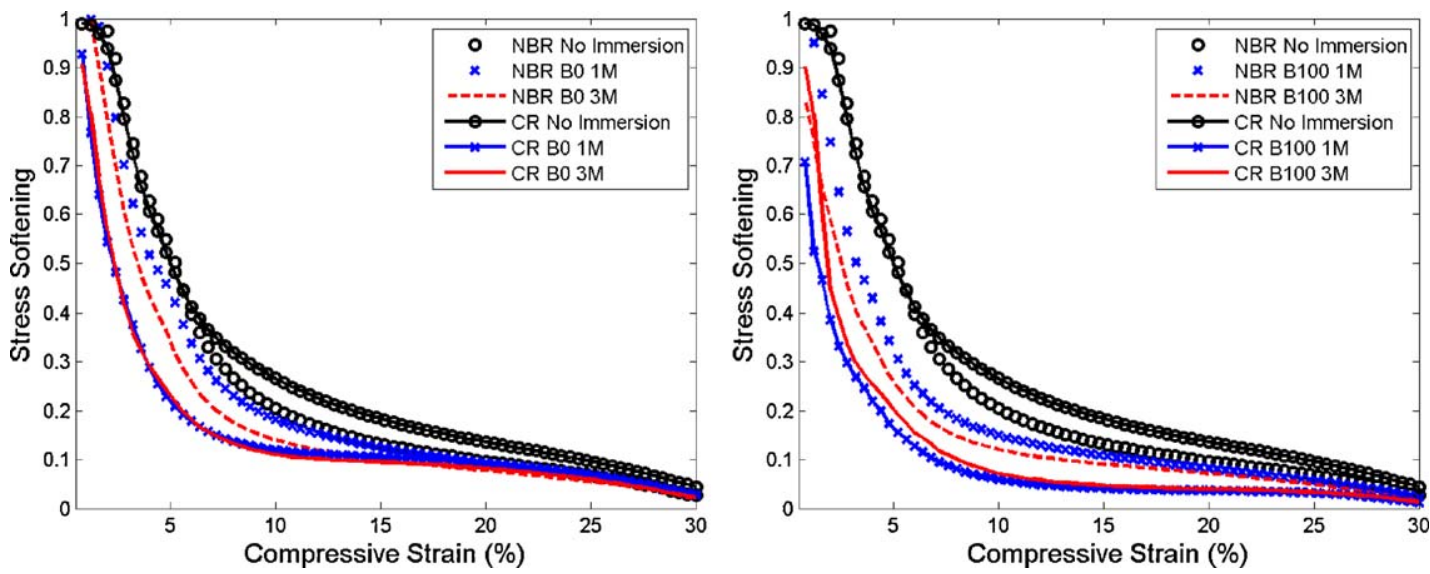

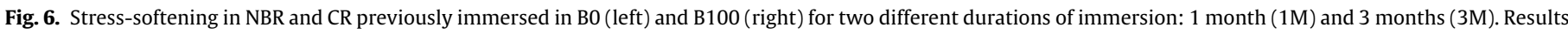
correspond to pre-compressive strain of $2 \%$. 

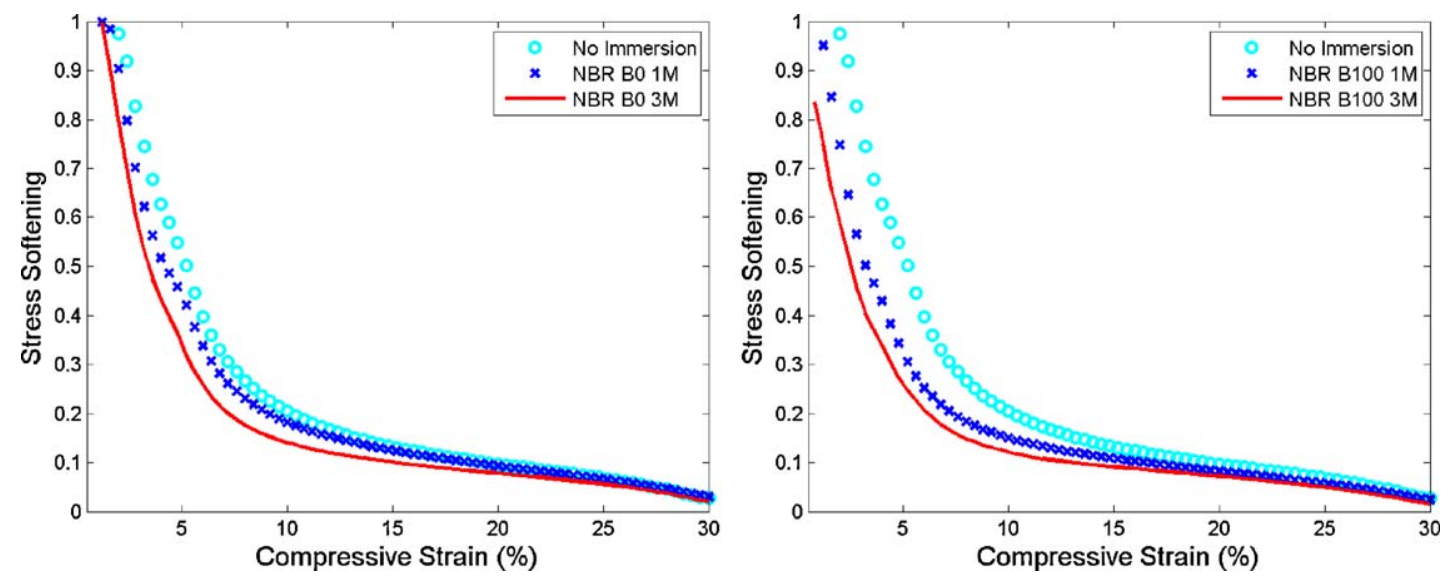

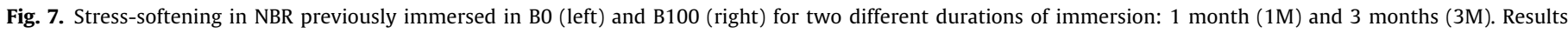
correspond to pre-compressive strain of $2 \%$.
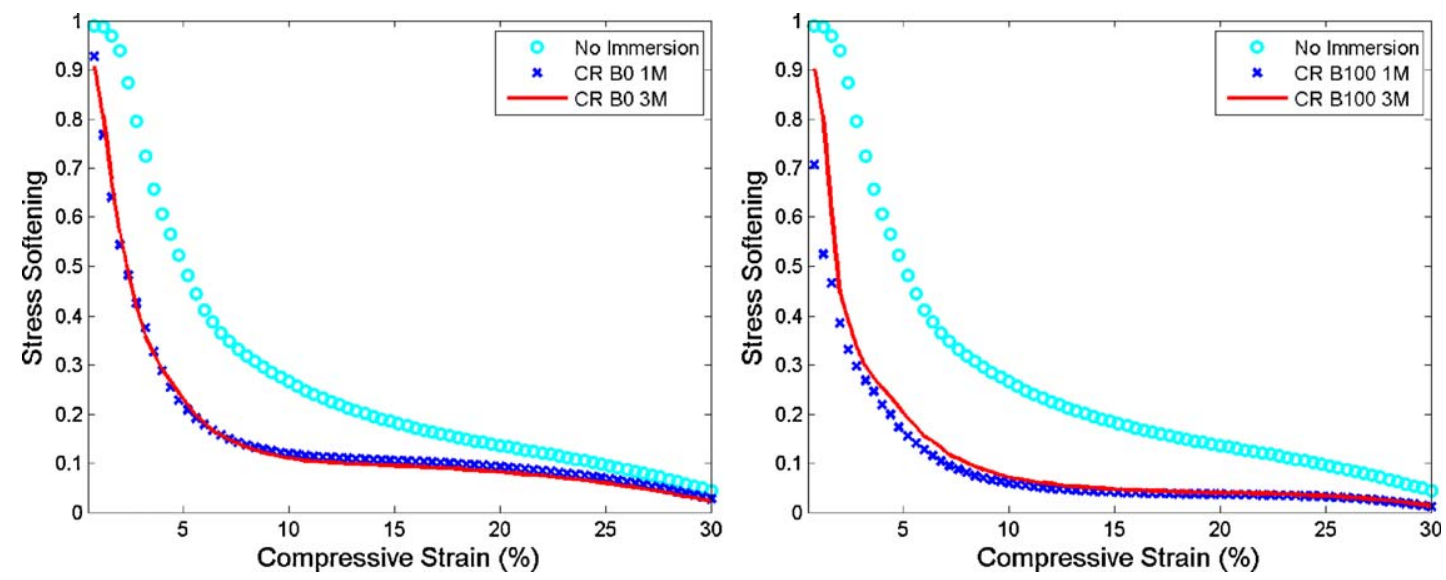

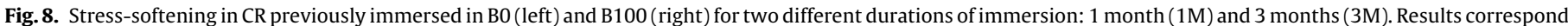
to pre-compressive strain of $2 \%$.

1 month in either B0 or B100, the stress-softening decreases significantly in CR and becomes lower than that of NBR. In NBR, for a compressive strain of $10 \%$, the amount of stress-softening drops from $20 \%$ at dry state to $18 \%$ and $15 \%$ at swollen state (immersed in B0 and B100 respectively for 1 month) as presented in Fig. 7. Increasing the duration of immersion from 1 month to 3 months yields to a further decrease of stress-softening to around $15 \%$ and
$12 \%$ in $\mathrm{B} 0$ and $\mathrm{B} 100$ respectively. Referring to Fig. 2 , this corresponds to the swelling level of $11 \%$ and $18 \%$ respectively.

In the case of $C R$, at applied compressive strain of $10 \%$, the amount of stress-softening changes from $28 \%$ for dry state to only $12 \%$ and $8 \%$ when it is immersed respectively in B0 and B100 for 1 month as shown in Fig. 8. Note that in the latter condition, the volume change exhibited by the material is around $18 \%$ and $64 \%$
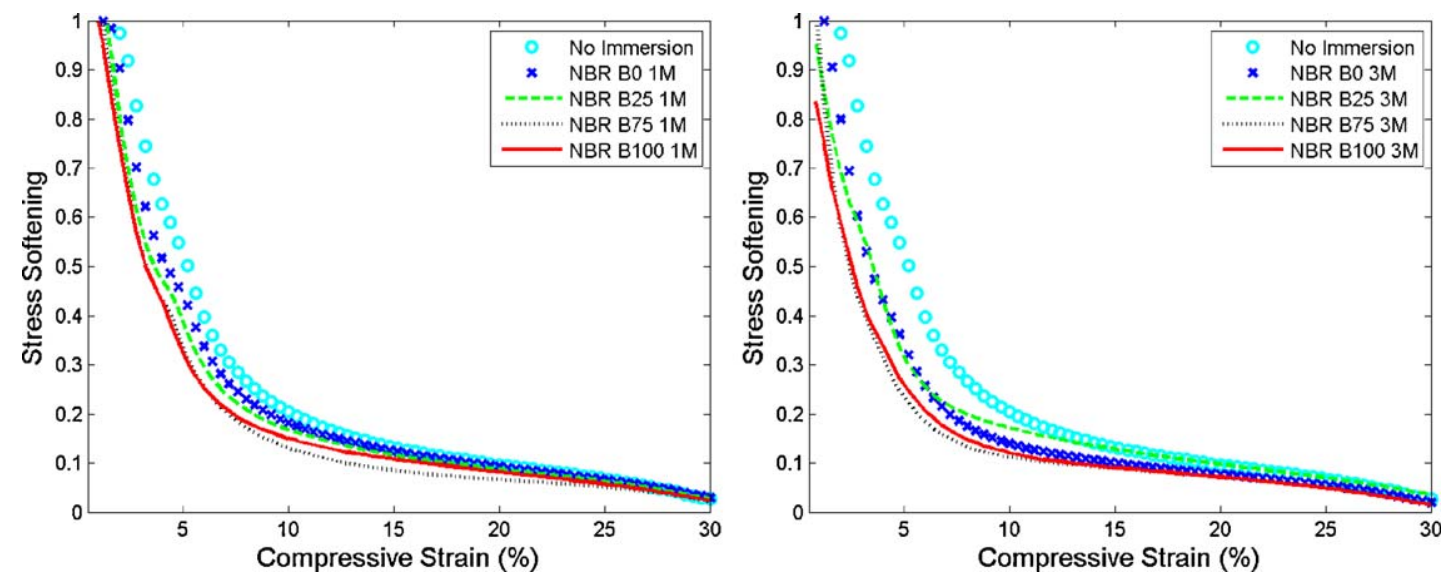

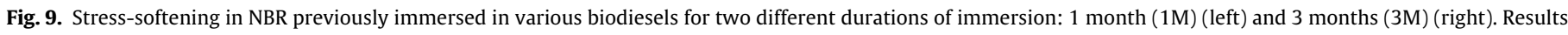
correspond to pre-compressive strain of $2 \%$. 

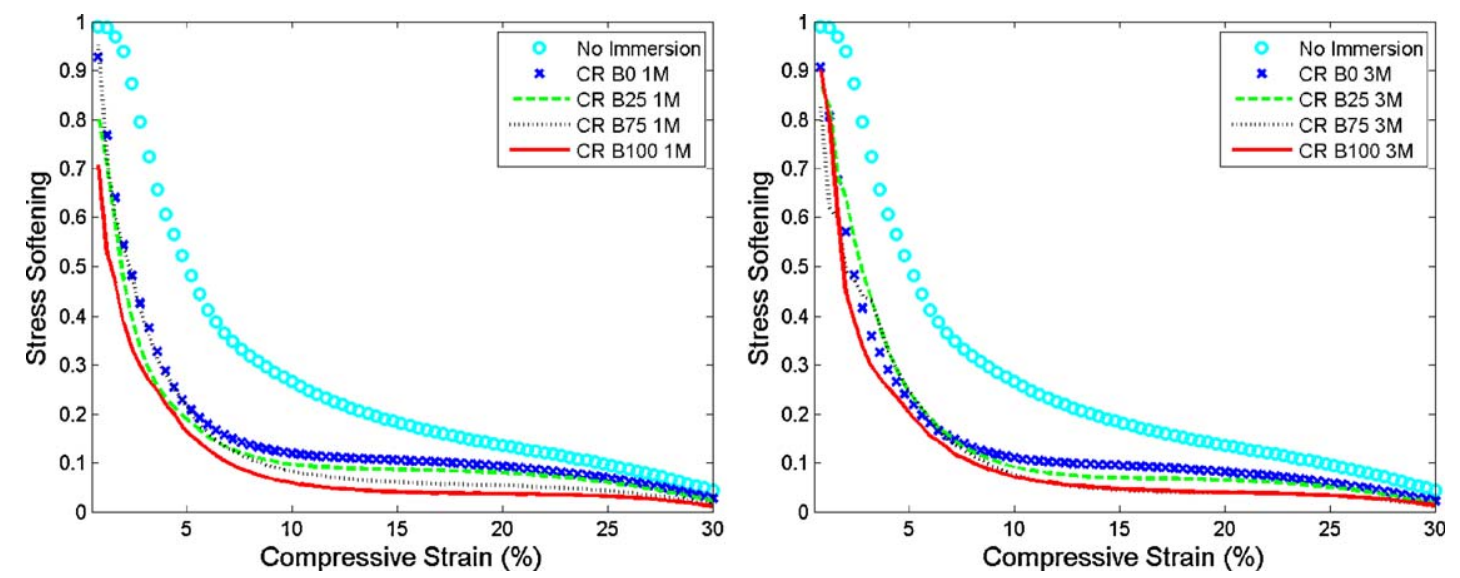

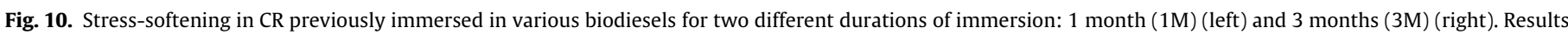
correspond to pre-compressive strain of $2 \%$.

respectively (see Figure 2). Increasing the duration of immersion from 1 month to 3 months yields to a significant increase in the volume change to around $24 \%$ and $90 \%$ in B0 and B100 respectively. However, the level of stress-softening appears to be unaffected by the corresponding further increase in swelling. Finally, the effect of biodiesel content on stress-softening in NBR and CR is presented in Fig. 9 and Fig. 10. In these figures, it is found that for both materials, the increase in the content of biodiesel decreases the level of stress-softening.

To close the paper, it is to note that all inelastic phenomena, e.g. stress-softening and mechanical hysteresis, in rubbers resulting from cyclic loading conditions appear to diminish significantly due to the presence of liquids, i.e. the macroscopic mechanical response of swollen rubbers approaches the response of hyperelastic materials. Nevertheless, the physical mechanism by which the presence of liquids modify the mechanical response under the above loading condition remains unknown.

\section{Conclusion}

In this work, the interaction between diffusion of liquids and large strain in rubber, and its resulting mechanical response under cyclic loading conditions were investigated. Two types of rubber were considered: NBR and CR. For given biodiesel content and duration of exposure, it was found that $\mathrm{CR}$ experienced higher changes in volume than NBR. Pre-compressive strain gave restriction for diffusion of liquids. Moreover, for a given duration of immersion, higher content of biodiesel yields to higher level of swelling in both rubbers.

Under cyclic loading conditions, inelastic phenomena in swollen rubbers appeared to be significantly smaller than that of dry rubber, i.e. smaller stress-softening and mechanical hysteresis were recorded. The increase in the content of biodiesel decreased further the aforementioned phenomena. More extensive studies on the physical mechanism by which the presence of liquids modify the mechanical response under cyclic loading condition are needed in the near future.

\section{Acknowledgments}

The authors greatly appreciate the financial support of this research from Institute of Research Management and Consultancy, University of Malaya under University Research Grant (grant no. RG083/10AET). This work was also funded by the Ministry of Higher Education Malaysia through High Impact Research Grant HIR-MOHE D000008-16001.

\section{References}

Abu-Abdeen, M., 2010. Single and double-step stress relaxation and constitutive modeling of viscoelastic behavior of swelled and un-swelled natural rubber loaded with carbon black. Mater. Des. 31, 2078-2084.

Andriyana, A., Saintier, N., Verron, E., 2010. Configurational mechanics and critica plane approach: concept and application to fatigue failure analysis of rubberlike materials. Int. J. Fatigue 32, 1627-1638.

Baek, S., Srinivasa, A.R., 2004. Diffusion of a fluid through an elastic solid undergoing large deformation. Int. J. Non-Lin. Mech 39, 201-218.

Bergström, J.S., Boyce, M.C., 2000. Large strain time-dependent behavior of filled elastomers. Mech. Mater. 32, 627-644.

Bouasse, H., Carriére, Z., 1903. Courbes de traction du caoutchouc vulcanisé. Ann. Fac. Sci. Toulouse 5, 257-283.

Callister, W., 2007. Materials Science and Engineering: An Introduction. Wiley.

Chai, A.B., Andriyana, A., Verron, E., Johan, M.R., Haseeb, A.S.M.A., 2011. Development of a compression test device for investigating interaction between diffusion of biodiesel and large deformation in rubber. Polym. Test. 30, 867-875.

Chester, S.A., Anand, L., 2010. A coupled theory of fluid permeation and large deformations for elastomeric materials. J. Mech. Phys. Solids 58, 1879-1906.

Deng, H., Pence, T.J., 2010. Shear induced loss of saturation in a fluid infused swollen hyperelastic cylinder. Int. J. Eng. Sci. 48, 624-646.

Diani, J., Fayolle, B., Gilormini, P., 2009. A review on the Mullins effect. Eur. Polym. J. $45,601-612$

Dorfmann, A., Ogden, R.W., 2004. A constitutive model for the Mullins effect with permanent set in particle-reinforced rubber. Int. J. Solids Struct. 41, 1855-1878.

Duda, F.P., Souza, A.C., Fried, E., 2010. A theory for species migration in a finitely strained solid with application to polymer network swelling. J. Mech. Phys. Solids 58, 515-529.

Flory, P., 1953. Principles of Polymer Chemistry. Cornell University Press, Ithaca, NY Haseeb, A.S.M.A., Masjuki, H.H., Siang, C.T., Fazal, M.A., 2010. Compatibility of elastomers in palm biodiesel. Renew. Energy 35, 2356-2361.

Hong, W., Zhao, X., Zhou, J., Suo, Z., 2008. A theory of coupled diffusion and large deformation in polymeric gels. J. Mech. Phys. Solids 56, 1779-1793.

Jayed, M.H., Masjuki, H.H., Kalam, M.A., Mahlia, T.M.I., Husnawan, M., Liaquat A.M., 2011. Prospects of dedicated biodiesel engine vehicles in Malaysia and Indonesia. Renew. Sust. Energy Rev 15, 220-235.

Lion, A., 1997. On the large deformation behaviour of reinforced rubber at different temperatures. J. Mech. Phys. Solids 45, 1805-1834.

Magryta, J., Debek, C., Debek, D., 2006. Mechanical properties of swelled vulcanizates of polar diene elastomers. J. Appl. Polym. Sci. 99, 2010-2015.

Mars, W.V., Fatemi, A., 2002. A literature survey on fatigue analysis approaches for rubber. Int. J. Fatigue 24, 949-961.

Mullins, L., 1948. Effect of stretching on the properties of rubber. Rubber Chem. Technol. 21, 281-300.

Soares, J.S., 2009. Diffusion of a fluid through a spherical elastic solid undergoing large deformations. Int. J. Eng. Sci. 47, 50-63.

Trabelsi, S., Albouy, P., Rault, J., 2003. Crystallization and melting processes in vulcanized stretched natural rubber. Macromolecules 36, 7624-7639.

Trakarnpruk, W., Porntangjitlikit, S., 2008. Palm oil biodiesel synthesized with potassium loaded calcined hydrotalcite and effect of biodiesel blend on elastomer properties. Renew. Energy 33, 1558-1563.

Treloar, L., 1975. The Physics of Rubber Elasticity. Oxford University Press, London.

Verron, E., 2003. Modélisation du comportement des structures et des matériaux élastomères. Ecole Centrale de Nantes, France. Habilitation (HDR) Thesis.

Verron, E., Andriyana, A., 2008. Definition of a new predictor for multiaxial fatigue crack nucleation in rubber. J. Mech. Phys. Solids 56, 417-443.

Zuyev, Y.S., Pravednikova, S.I., Zherebkova, L.S., Zaitseva, V.D., 1964. The tearresistance of rubbers in the presence of physically aggressive media. Polym. Sci. USSR 5, 269-276. 